NASA Technical Memorandum 106217

\title{
System Overview on Electromagnetic Compensation for Reflector Antenna Surface Distortion
}

R.J. Acosta, A.J. Zaman, and J.D. Terry

Lewis Research Center

Cleveland, Ohio

Prepared for the 1993 IEEE AP-S International Symposium

Ann Arbor, Michigan, June 27-July 2, 1993 

, 


\title{
SYSTEM OVERVIEW ON ELECTROMAGNETIC COMPENSATION FOR REFLECTOR ANTENNA SURFACE DISTORTION
}

\author{
R.J. Acosta, * A.J. Zaman and J.D. Terry \\ National Aeronautics and Space Administration \\ Lewis Research Center \\ Cleveland, Ohio 44135
}

\section{Introduction}

The system requirements and hardware implementation for electromagnetic compensation of antenna performance degradations due to thermal effects has been investigated. Future commercial space communication antenna systems will utilize the $20 / 30 \mathrm{GHz}$ frequency spectrum and support very narrow multiple beams ( 0.3 degrees) over wide angle field of view (15-20 beamwidth)[1]. On the ground, portable and inexpensive very small aperture terminals (VSAT) for transmitting and receiving video, facsimile and data will be employed. These types of communication system puts a very stringent requirement on spacecraft antenna beam pointing stability $(<.01$ degrees), high gain (>50 dB) and very low sidelobes $(<-25 \mathrm{~dB})$.

Thermal analysis performed on the advanced communication technology satellite (ACTS) has shown that the reflector surfaces, the mechanical supporting structures and metallic surfaces on the spacecraft body will distort due thermal effects from a varying solar flux [2]. The antenna performance characteristics (e.g., pointing stability, gain, sidelobe, etc.) will degrade due to thermal distortion in the reflector surface and supporting structures. Specifically, antenna RF radiation analysis has shown that pointing error is the most sensitive antenna performance parameter to thermal distortions. other antenna parameters like peak gain, cross polarization level (beam isolation) and sidelobe level will also degrade with thermal distortions [2]. In order to restore pointing stability and in general antenna performance several compensation methods have been proposed [3]. In general these compensation methods can be classified as being either of mechanical or electromagnetic type. This paper will address only the later one. In this approach an adaptive phased array antenna feed is used to compensate for the antenna performance degradation.

Extensive work has been devoted to demonstrate the feasibility of adaptive feed compensation on space communication antenna systems [4]. This paper addresses the system requirements for such a system and identify candidate technologies (analog and digital) for possible hardware implementation.

\section{Thermal Distortion Analysis and Discussion}

The system requirements for implementing electromagnetic compensation may be derived by considering the ACTs multibeam antenna system configuration and a 19 element phased array feed [5]. The ACTS multibeam antenna system is a dual reflector cassegrain system (fig. 1). Thermal distortions are simulated by varying the amplitude of a sinusoidal surface superimposed over the main reflector. Peak distortion considered in the analysis varied between 0 mils to 400 mils. Table 1 summarizes the antenna performance parameters (gain, sidelobe level, pointing, etc.) as a function of the peak distortion. Table 2 shows the compensated antenna performance parameter by using a 19 element and a 7 element phased array feed.

The RF antenna performance simulation results indicated that beam pointing and end of coverage (EOC) can be severely be affected by thermal distortions. It is shown that the EOC can be degraded by as much as $-10 \mathrm{~dB}$ for a peak distortion of $202 \mathrm{mils}$. If electromagnetic compensation is used the EOC gain can be recovered to within $0.5 \mathrm{~dB}$ 
of the undistorted value.

Another antenna parameter sensitive to thermal distortions is beam isolation. The RF antenna performance simulation showed that beam isolation under thermal distortion was in the order of $-10 \mathrm{~dB}$. Beam isolation is defined as the interference polarization component of adjacent beams in a multibeam system. The typical specification for an ACTS type system is $-25 \mathrm{~dB}$. With electromagnetic compensation the beam isolation can be recovered to the specified level of -25 dB.

An infinite resolution in amplitude and phase control of the feed array element was assumed for all RF antenna performance simulations. For example, for a peak distortion of 50 mils it was found that a very fine differential amplitude control $(0.3 \mathrm{~dB})$ and phase control ( 3 degrees) were necessary for each array feed element. If an analog phased array feed is used a 12 bit MMIC phase shifter and 8 bit SSPA amplitude resolution are required for compensation. If a digital beamforming array is used a 12 bit A/D converter with a $1 \mathrm{GHz}$ bandwidth is required for compensation.

\section{Analog Compensation system Implementation}

A possible analog compensation implementation is presented in figure 2 [3]. The compensating phased array includes a phase detector, an amplitude detector and phase conjugator. These modules are usually not included in a typical analog beamforming phased array. $A$ possible phase detector module architecture can be described as follows; The incoming RF signal at each array element is coherently detected and down converted to intermediate frequency (IF) [6]. The module performs a product integration of the IF signal with locally generated in-phase and quadrature IF signals. The results are used to estimate the phase of the received signal.

The adaptive compensation antenna system utilizing an analog phased array feed can be described as follows; a pilot signal from the desired ground station is received by the spacecraft receiving antenna and is detected by the phased array. The compensating analog phased array feed acquires the amplitude and phase information at each element location, and their conjugate value serves as the transmitting compensating excitations.

The system requirements can be established by considering the 58 mill distortion case. For this value the phase detector module will require relative phase resolution of 3 degrees and the amplitude detector module will require amplitude resolution in the order of $0.3 \mathrm{~dB}$.

\section{Digital Compensation System Implementation}

A block diagram for a digital compensating array implementation is presented in figure 3. Electromagnetic compensation with the digital signal processing arrays is performed quite differently than its analog counterpart. The compensating system is described as follows; In the received mode, the received signal output from a the desired ground station is optimized with respect to the noise output. The optimization algorithm will estimate an optimum set of excitation coefficients for maximum signal to noise output. No need for pilot signal to be send from the ground station is necessary in this compensation format and no need for extra hardware modules for detecting the received phase and amplitude of each array element. In the transmit mode the corresponding optimum set of complex excitation coefficients found in the receiving mode are used to transmit the compensated antenna pattern. 
By using digital circuitry it is not difficult to resolve differential amplitudes in the order of $0.3 \mathrm{~dB}$ and differential phase in the order 3 degrees. The technical limitations of using digital beamforming phased arrays at the present time arises when bandwidth of $1 \mathrm{Ghz}$ or greater are required. Present technology in A/D or D/A are far from meeting these requirements which limits the amount of information that can be transmitted using digital beamforming arrays.

\section{Future Work}

We have investigated the system requirements for possible implementations of compensation scheme for advanced space communication systems. We also realize that presently the technology is far from being able to support such demanding system requirements. With the advent of low temperature superconductivity (ITS) for near term applications and high temperature superconductivity (HTS) for far term applications, higher bandwidth ( $2-5 \mathrm{Ghz}$ ) and computing speed (.001 microseconds) can be achieved with digital circuitry. This innovative technologies provides the digital signal processing unlimited performance enhancements. In the near future technologies like LTS and even HTS might make the concept of adaptive compensation more robust for applications in future space communication antenna systems.

\section{References}

[1] D.I.Wright, J.R. Balombin and P.Y. Sohn, "Advanced Communica tion Technology Satellite (ACTS) and Potential system Applications, "Proceeding of IEEE, Vol. 78, No. 7, 1990.

[2] R.J. Acosta, J. Larko, A. Narvaez, and A. Lagin, "Advanced Communications Communication Technology satelite (ACTS) Multibeam Antenna Analysis and Experiment," IEEE AP-S, July $18-25,1992$.

[3] R. J. Acosta and A. Zaman, "Adaptive Feed Array Compensation System for Reflector Antenna Surface Distortion," IEEE AP-S June 26-30, 1989

[4] A. Zaman, Y. Rahmat-Samii and K. Woo," Experimental Code Verification Results for Reflector Antenna Distortion Compensation by Array Feeds," 14th AIAA Conference on Communications sateliite system, Washington, DC, March, 1992.

[5] F.A. Regier, "The ACTS Multibeam Antenna," IEEE Transaction on Microwave Theory and Techniques, Vol. 40, No. 6, June 1992.

[6] J. D. Terry, "A Prototype Automatic Phase Compensation Module," NASÁ Technical Memorandum 105930, December 1992. 


\section{TABLE 1 - Antenna Performance Parameters}

\begin{tabular}{|c|c|c|c|c|}
\hline $\begin{array}{c}\text { Parameter } \\
\begin{array}{c}\text { Distortion } \\
\text { (mills) }\end{array}\end{array}$ & $\begin{array}{c}\text { Directivity } \\
(\mathrm{dB})\end{array}$ & $\begin{array}{c}\text { Sidelobe } \\
\text { Level } \\
(\mathrm{dB})\end{array}$ & $\begin{array}{c}\text { Pointing } \\
\text { Error } \\
(\text { Deg.) }\end{array}$ & $\begin{array}{c}\text { Cross-Pol } \\
(\mathrm{dB})\end{array}$ \\
\hline 0.0 & 54.00 & -24.0 & 0.000 & -28.0 \\
\hline 29.0 & 53.20 & -22.0 & 0.000 & -24.0 \\
\hline 58.0 & 52.40 & -19.0 & 0.003 & -22.0 \\
\hline 87.0 & 51.60 & -16.0 & 0.008 & -20.0 \\
\hline 116.0 & 50.80 & -14.0 & 0.009 & -18.0 \\
\hline 144.0 & 50.00 & -12.0 & 0.012 & -15.0 \\
\hline 173.0 & 49.20 & -11.0 & 0.019 & -13.0 \\
\hline 202.0 & 49.00 & -8.0 & 0.030 & -10.0 \\
\hline
\end{tabular}


TABLE 2 - Compensated Antenna Performance Parameter

\begin{tabular}{|c|c|c|c|c|c|c|c|}
\hline $\begin{array}{c}\text { Parameter } \\
\text { Distortion } \\
\text { (mills) }\end{array}$ & $\begin{array}{c}\text { Directivity } \\
\text { (dB) }\end{array}$ & \multicolumn{2}{|c|}{$\begin{array}{c}\text { Compensated } \\
\text { Directivity }\end{array}$} & \multicolumn{2}{c|}{$\begin{array}{c}\text { Compensated } \\
\text { Cross-Pol }\end{array}$} & \multicolumn{2}{c|}{$\begin{array}{c}\text { Pointing } \\
\text { Error }\end{array}$} \\
\hline 0.0 & 54.00 & 54.00 & 54.00 & -24.0 & -24.0 & 0.00 & 0.00 \\
\hline 29.0 & 53.20 & 54.00 & 54.00 & -21.8 & -23.5 & 0.00 & 0.00 \\
\hline 58.0 & 52.40 & 54.00 & 54.00 & -21.5 & -23.6 & 0.00 & 0.00 \\
\hline 87.0 & 51.60 & 53.70 & 54.00 & -21.3 & -23.6 & 0.00 & 0.00 \\
\hline 116.0 & 50.80 & 53.00 & 53.99 & -21.2 & -23.5 & 0.01 & 0.01 \\
\hline 144.0 & 50.00 & 52.99 & 53.99 & -20.7 & -23.5 & 0.01 & 0.01 \\
\hline 173.0 & 49.20 & 52.90 & 53.99 & -20.7 & -23.2 & 0.02 & 0.01 \\
\hline 202.0 & 49.00 & 52.50 & 53.99 & -20.7 & -23.2 & 0.02 & 0.01 \\
\hline
\end{tabular}




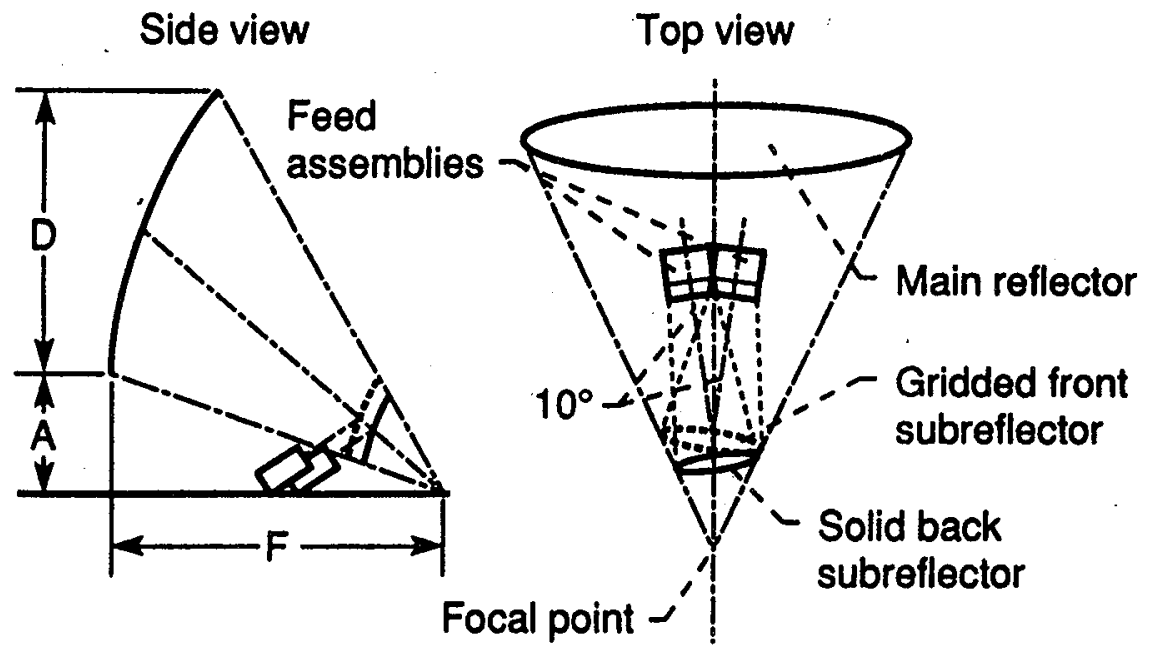

\begin{tabular}{|l|r|r|}
\hline \multicolumn{1}{|c|}{ Parameter } & \multicolumn{1}{|c|}{$20 \mathrm{GHz}$} & $30 \mathrm{GHz}$ \\
\hline D (Main reflectordiameter, inches) & 129.9 & 86.6 \\
A (Offset distance, inches) & 50.0 & 44.0 \\
F (Main reflector focal length, inches) & 132.0 & 88.0 \\
\hline Gridded front subreflector & & \\
Focal length, inches & 69.0 & 44.5 \\
Magnification factor & 2.0 & 2.0 \\
\hline Solid back subreflector & & \\
Focal length, inches & 52.4 & 32.4 \\
Magnification factor & 2.0 & 2.0 \\
\hline
\end{tabular}

Figure 1. ACTS Multibeam Antenna Geometry 


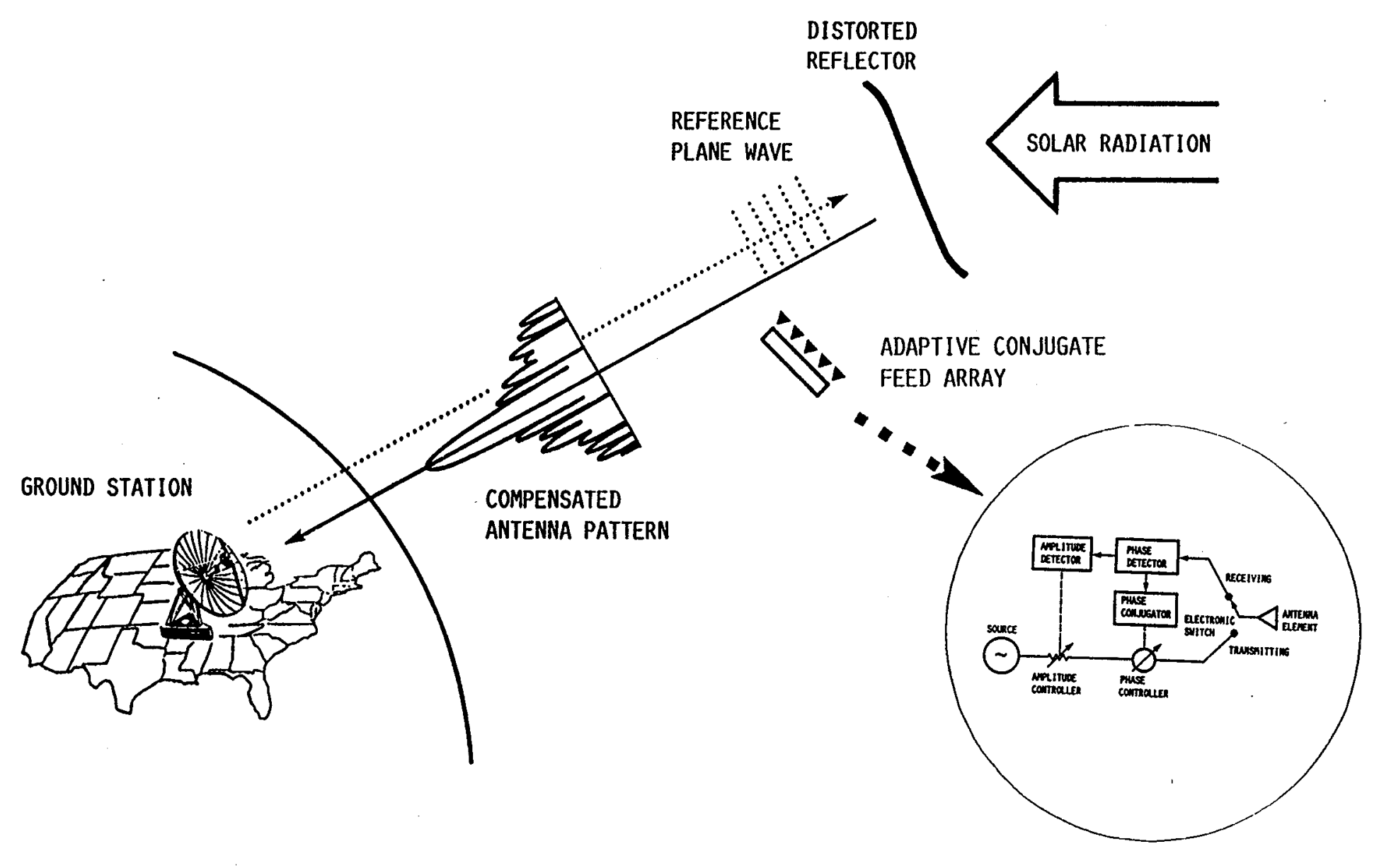

Figure 2. Analog Compensation System Implementation 


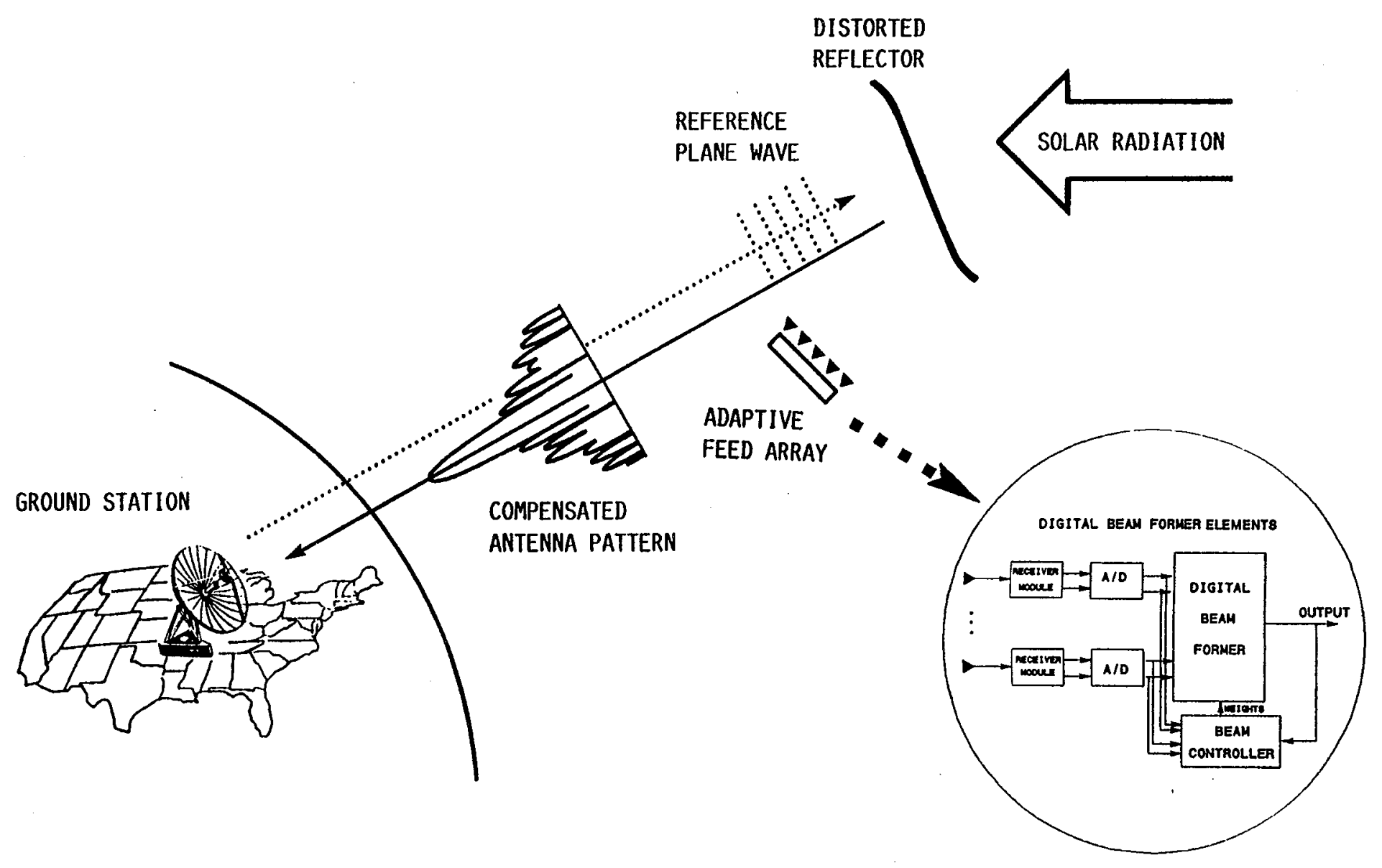

Figure 3. Digital Compensation System Implementation 

Public reporting burden for this collection of information is estimated to average 1 hour per response, including the time for reviewing instructions, searching existing data sources, gathering and maintaining the data needed, and completing and reviewing the collection of information. Send comments regarding this burden estimate or any other aspect of this collection of information including suggestions for reducing this burden, to Washington Headquarters Services, Directorate for Information Operations and Reports, 1215 Jefferson Davis Highway, Suite 1204, Arlington, VA 22202-4302, and to the Office of Management and Budget, Paperwork Reduction Project (0704-0188), Washington, DC 20503.

\begin{tabular}{|c|c|c|}
\hline $\begin{array}{c}\text { 1. AGENCY USE ONLY (Leave blank) } \\
\text { 2. REPORT DATE } \\
\text { June } 1993\end{array}$ & $\begin{array}{c}\text { 3. REPORT TYPE AND DATES COVERED } \\
\text { Technical Memorandum }\end{array}$ \\
\hline
\end{tabular}

\section{TITLE AND SUBTITLE}

5. FUNDING NUMBERS

System Overview on Electromagnetic Compensation for Reflector Antenna Surface Distortion

6. AUTHOR(S)

R.J. Acosta, A.J. Zaman, and J.D. Terry

- WU-579-50-00

\section{PERFORMING ORGANIZATION NAME(S) AND ADDRESS(ES)}

National Aeronautics and Space Administration

Lewis Research Center

Cleveland, Ohio 44135-3191

8. PERFORMING ORGANIZATION REPORT NUMBER

E-7928

9. SPONSORING/MONITORING AGENCY NAME(S) AND ADDRESS(ES)

10. SPONSORING/MONITORING AGENCY REPORT NUMBER

National Aeronautics and Space Administration

Washington, D.C. 20546-0001

NASA TM-106217

\section{SUPPLEMENTARY NOTES}

Prepared for the 1993 IEEE AP-S International Symposium, Ann Arbor, Michigan, June 27-July 2, 1993. Responsible person, R.J. Acosta, (216) 433-6640.

12a. DISTRIBUTION/AVAILABILITY STATEMENT

12b. DISTRIBUTION CODE

Unclassified -Unlimited

Subject Category 17

\section{ABSTRACT (Maximum 200 words)}

The system requirements and hardware implementation for electromagnetic compensation of antenna performance degradations due to thermal effects has been investigated. Future commercial space communication antenna systems will utilize the $20 / 30 \mathrm{GHz}$ frequency spectrum and support very narrow multiple beams ( 0.3 degrees) over wide angle field of view (15-20 beamwidth)[1]. On the ground, portable and inexpensive very small aperture terminals (VSAT) for transmitting and receiving video, facsimile and data will be employed. These types of communication system puts a very stringent requirement on spacecraft antenna beam pointing stability (<.01 degrees), high gain $(>50 \mathrm{~dB})$ and very low sidelobes $(<-25 \mathrm{~dB})$. Thermal analysis performed on the advanced communication technology satellite (ACTS) has shown that the reflector surfaces, the mechanical supporting structures and metallic surfaces on the spacecraft body will distort due thermal effects from a varying solar flux [2]. The antenna performance characteristics (e.g., pointing stability, gain, sidelobe, etc.) will degrade due to thermal distortion in the reflector surface and supporting structures. Specifically, antenna RF radiation analysis has shown that pointing error is the most sensitive antenna performance parameter to thermal distortions. Other antenna parameters like peak gain, cross polarization level (beam isolation) and sidelobe level will also degrade with thermal distortions [2]. In order to restore pointing stability and in general antenna performance several compensation methods have been proposed [3]. In general these compensation methods can be classified as being either of mechanical or electromagnetic type. This paper will address only the later one. In this approach an adaptive phased array antenna feed is used to compensate for the antenna performance degradation. Extensive work has been devoted to demonstrate the feasibility of adaptive feed compensation on space communication antenna systems [4]. This paper addresses the system requirements for such a system and identify candidate technologies (analog and digital) for possible hardware implementation.

14. SUBJECT TERMS

Multibeam antenna; Reflector antenna; Phased array

15. NUMBER OF PAGES

10

10

\section{SECURITY CLASSIFICATION OF REPORT}

Unclassified

\section{SECURITY CLASSIFICATION OF THIS PAGE \\ Unclassified}

19. SECURTYY CLASSIFICATION OF ABSTRACT Unclassified 